To cite this article: Daria Zimina, Glenn Ballard \& Christine Pasquire (2012): Target value design: using collaboration and a lean approach to reduce construction cost, Construction Management and Economics, 30:5, 383-398

To link to this article: http://dx.doi.org/10.1080/01446193.2012.676658

\title{
Target value design: using collaboration and a lean approach to reduce construction cost.
}

Daria Zimina ${ }^{1}$, Glenn Ballard ${ }^{2}$ b \& Christine Pasquire ${ }^{3}$

Target Costing is an effective management technique that has been used in manufacturing for decades to achieve cost predictability during new products development. Adoption of this technique promises benefits for the construction industry as it struggles to raise the number of successful outcomes and certainty of project delivery in terms of cost, quality and time. Target Value Design is a management approach that takes the best features of Target Costing and adapts them to the peculiarities of construction. In this paper the concept of Target Value Design is introduced based on the results of action research carried out on 12 construction projects in the USA. It has been shown that systemic application of Target Value Design leads to significant improvement of project performance - the final cost of projects was on average $15 \%$ less than market cost. The construction industry already has approaches that have similarities with elements of the Target Value Design process or uses the same terminology, e.g. Partnering and Target Cost Contracts, Cost planning, etc. Following an exploration of the similarities and differences Target Value Design is positioned as a form of Target Costing for construction that offers a more reliable route to successful projects outcomes.

Keywords: target cost, lean construction, cost planning, target value design.

\section{Introduction}

Target Costing (TC) appeared in the manufacturing industry in the early 1930s (Feil et al., 2004) and has proved to be a powerful strategic instrument for management and profit planning (Cooper and Kaplan, 1999). Since then it has been used in

\footnotetext{
${ }^{1}$ Department of Civil and Building Engineering, Loughborough University, Loughborough, UK ${ }^{2}$ Department of Civil and Environmental Engineering, University of California at Berkeley, Berkeley, USA

${ }^{3}$ School of Architecture, Design and the Build Environment, Nottingham Trent University
} 
manufacturing to achieve cost predictability during new product development so that new products and services both meet market determined price and provide financial returns. The main principle of Target Costing is to make cost and value drive the design process instead of calculating the cost after design is complete.

Similarity in manufacturing product development and construction project delivery processes opens an opportunity for Target Costing in construction. However in spite of potential benefits there is no evidence of this practice being taken up by the industry of Europe or the USA. In Japan about $15 \%$ of construction companies use Target Costing from manufacturing (Jacomit et al., 2008). Academic literature provides only scarce reports on theoretical and practical issues of the method (Nicolini, 2000; Pennanen et al., 2010; Knott, 1996).

Insights into the adaptation of the manufacturing Target Costing method to the project-based environment of construction can be drawn directly from 12 practical cases of Target Value Design (TVD). TVD takes a view of construction as a complex system which includes project definition, design and construction stages. It correlates closely with lean thinking in design and construction.

Many construction cost and project management practices already use "target costing" terminology or repeat TVD in some part of the process. "Target costing" stands for a range of techniques and methods applied as part of traditional cost management, such as contract and cost management and target cost contract. Thus there is a possibility to overlook the innovation offered by the TVD approach as construction practitioners and academics might believe "we are already doing that". By analysis of literature and empirical observation of current cost and project management practices the answers to the following research question is investigated: is TVD really different from current practices and why? The conclusion is TVD and current contract and cost 
management techniques are essentially different in both managerial philosophy and practical implementation.

The following definitions of the terms are used in the paper:

- Target Costing - is the original cost and profit management concept developed in manufacturing.

- Target Value Design - is an adaptation of the original Target Costing concept to the construction industry peculiarities.

- Target cost contracts (TCCs) - a family of contracts with a pain/gain share mechanism.

- Cost target - a desirable figure for project completion.

- Target cost/target - the cost management goal used in TVD.

\section{Methodology and the research method}

The core material for this paper was provided by the TVD research project, which has been carried out since 2002. The research problem for the project was identified as a real life issue - how can we cure the shortcomings of the mainstream cost and contract management approach that result in regular cost overruns and client dissatisfaction? Upon discovery that this problem was successfully managed in manufacturing using Target Costing (Ballard and Reiser, 2004), and recognising the need to adapt practices when transferred to a new domain, a decision was made to assume a more proactive engineering position, rather than a non-interventionist purely scientific one. Action research was chosen as a research method.

The name "action research" was introduced by Kurt Lewin to describe a process of organisational change that uses "... a spiral of steps, each of which is composed of a circle of planning, action, and fact-finding about the result of the action" (Lewin, 1946). In action research the researcher's traditional role of observer and analyst is expanded to 
include participation in what is being observed and analysed, in process design (which may be understand as a hypothesis to be tested in live environment), and planning how to test and evaluate the adequacy of the process (hypothesis) so designed. The objective of the method is to develop a practice, hence historically it is strongly linked to organisational development/organisational change (French and Bell, 1973). The choice of action research for this study is justified by correspondence of the study objectives to change a social practice and to include the researchers in the 'experimentation' and development of that practice - with the method's objectives and characteristics.

TVD research has been undertaken within the existing framework of Lean Project Delivery (Ballard et al., 2000). Epistemologically action research is consistent with the Lean management philosophy as for both the most efficient way to acquire knowledge is by participant experiment in a live environment and then systemically reflect on what works and what does not. Central to both is the Plan-Do-Check-Act cycle developed by Walter Shewhart (1931).

Following the key concern for action researchers to develop practical and conceptual contributions by doing research with, rather than on people (Reason and Bradbury, 2007), the TVD research group established long-term collaboration with a number of client and construction industry companies that were willing to experiment with new approaches. Among those is Sutter Health, a healthcare service provider in California, US, that adopted lean strategy (and TVD) since 2004 and the Boldt Company, a contractor whose key developmental areas are financial management, production management and designing to target cost. The researchers were directly involved and worked with the project teams almost on a daily basis, acting as informers of the theory of Target Costing, helping with execution of the practical trials, making adjustments and collecting data. 
To this date 12 TVD projects have been completed and the results reported in this paper are based on the learning obtained from those. A detailed description of two case studies is provided. The Fairfield Medical Office Building project was chosen because it represents the first mature application of TVD, including a form of contract that integrated the project team organisationally and aligned commercial interests. The project has been constructed, enabling comparison of market benchmark cost, target cost, and actual cost at completion. The Cathedral Hill Hospital project, although not fully constructed, represents the most advanced application of TVD to date.

To accomplish the purpose of this paper a subproject of the TVD project was launched that included research of the mainstream commercial practice in the UK and the USA carried out through observations and interviews with management. Previous professional experience of the researchers as quantity surveyors and cost engineers contributed to a better understanding of the current state of the industry. Literature review was used to support the findings, as the processes of the mainstream commercial practice in the UK and the USA are relatively well documented with guidelines produced by professional institutions, professional literature and academic writings. An additional literature review was made on the topics of Target Costing in manufacturing, use of target cost contracts, and partnering. To ensure the constancy and accuracy of the research information the same researcher was involved throughout the data collection and analysis process of the TVD project and subproject.

\section{Target costing in manufacturing}

Target Costing was born in the manufacturing industry as a result of the search for a better cost management practice in new product development. It turned out to be a powerful strategic instrument for management and profit planning as it helps to ensure that new products and services meet market determined price and provide financial 
returns (Cooper and Kaplan, 1999). At the same time it promoted a different approach to design management where cost stops being just an outcome from the product design but instead becomes an input into the process (ibid).

Since the 1970s most companies in competitive industries have used some elements of Target Costing (Ansari et al., 2006). It is especially relevant to the sectors of high-technology consumer goods (automotive industry, digital equipment) and project based industries, such as shipbuilding, military manufacturing and construction. While invented in the western world as early as 1930s (Feil et al., 2004), TC has found better acceptance in Japan where more than $80 \%$ of the large manufacturers listed at the Tokyo Securities Market: Section 1, comprehensively rely on this strategy (Yoshikawa et al., 1995; Lockamy and Smith, 2000; Kato and Yoshida, 1998). TC was one of the factors that contributed to the rapid growth of competitive advantage of Japanese companies during 1960-1990s. In the western world Chrysler and Caterpillar attribute their financial turnarounds in the mid 1990s to the adoption of TC (Ansari et al., 2006).

Cooper and Slagmulder (1997) focus on the application of TC as a profit management technique. They define it as a process which ensures a new product can be produced at such cost that allows a planned level of profitability. It is assumed that the company sets long-term sales and profit goals, and structures product lines in accordance with those. New product development starts with deciding upon productlevel target cost, which is the maximum that can be spent for development, production, sales, distribution, and warranty. Lockamy and Smith (2000) note the priority of customer requirements over cost reduction per se, claiming that cost rationalisation, not minimisation, is the goal.

Target Costing is not limited to setting cost targets - it is an entire value chain approach to managing an enterprise. It is not an easy journey but one that takes longterm dedicated effort and commitment from people across all corporate processes 
(Rains, 2010). The TC system pays special attention to the design and development stage as it is taken as a fact that most of the future product costs are formed here. Close collaboration of all the departments and the supply chain early in the project development intersects with the lean concept of simultaneous engineering. Cross functional teams investigate not only aesthetic issues and functionality of the future product, but also manufacturability, procurement routes, life-cycle performance. To ensure manufacturability for example, production engineers work together with the design team. Sales manager brought into the product development stage are able to give valuable advises on market needs (Tani, 1995). Naturally it is the way to significant savings, as demonstrated by Kato (1993) on the example of leading Japanese manufacturers.

Target Costing is closely associated with inter-organisational cost management practices, e.g. in Håkansson and Lind (2006), Cooper and Slagmulder (2004), and Anderson (2006). Lockamy and Smith (2000) conclude that use of Target Costing can enhance a supply chain's ability to improve customer satisfaction. The issue has grown in importance with the global trend for outsourcing parts of the production cycle, which results in a higher share of the suppliers' cost in the total product cost (Carr and $\mathrm{Ng}$, 1995). The company's head office usually retains the function of setting a target involving suppliers in definition of cost and functionality goal for subassemblies (e.g., in a car, the engine, transmission, cooling system, air conditioning system, and audio system). Target Costing exercises can also proceed down to the supply chain, when “first-tier" suppliers invite their suppliers to work on target cost (Anderson, 2006). Monden and Hamada (2000), reviewing Target Costing practices employed by Japanese car manufacturers, note that it is not the final point of the cost management process. The wider concept of Total Cost Management also includes Kaizen Costing. Thus if Target Costing operates in the developing and designing phase, Kaizen Costing 
is applied to the manufacturing stage of both to recently developed or already established products. Kaizen Costing is a constant pursuit for perfection via small improvements in process and product which involves all hierarchical levels on the workplace.

The Target Costing concept is similar to the cost as an independent variable approach used by the U.S. Department of Defence and to the price-to-win philosophy used by a number of companies pursuing contracts involving development under contract (Crow, 2002). Summarising the above, TC in manufacturing is a strategy applied in long-term business planning. Normally it includes several other tools and methods, which are sometimes described as self-sufficient and associated with the narrow definition of target costing: value engineering, value analysis, design for manufacturability and assembly, simultaneous (concurrent) engineering, standardisation and others.

\section{Target Costing in construction}

Independently from manufacturing, construction has developed several practices that might be labelled Target Costing or might have similarities in process or organisational structure: contract management, cost planning, Design-Build-Own-Transfer (DBOT) and partnering projects, target cost contracts. Contract management, an inevitable part of any construction project, gives employment to quantity surveyors (QSs) or cost engineers. Prior to the tender each party seeks to establish what they will need to pay firstly to secure the contract and then to complete the work. It is rare that these two figures are the same given the way in which construction projects vary across their duration. In general the objective is to minimise purchase price from the supplier and to maximise cost recovery at every opportunity offered as a result of the variation to the 
project. Cost estimates become "targets" below which the work is purchased. For the contractor the skill in purchasing is viewed a primary contributor to project profit.

The cost planning process is a form of construction budgeting used by QSs (cost engineers). It includes several phases: client brief, procurement advice and budget; cost planning and control of the design stage; cost control of the production stages (Kirkham, 2007). During the first stage a cost analysis is performed to obtain market based cost information from similar completed projects and to prepare a preliminary cost model based on broad categories of building elements. At the design stage cost planning aims to provide a methodology to control the design process and stay within the client's budgetary requirements (according to $\mathrm{RICS}^{4}$ ). Thus it seems to repeat Target Costing in its aim to design a product (building) to a budget, rather than costing a design after it has been completed. In some cases, the project budget is kept within the amount agreed in the feasibility estimation through a team approach using value management (UK) or value engineering (US) (Pratt, 2004). At the construction stage a "contract target" item and work package "cost targets" often constitute part of the main contractors' cost control and reporting system adding to this mixture of terms.

Contract and cost management techniques can be applied under any procurement route in which design and construction stages are separated contractually or by practice. Cost targets are also a feature of the DBOT family of projects. These are different from the previous group as they aim to include contractors in the financial and design decision-making with the contractors providing the costs directly. The intention is that as the principal supply chain members are included as developers/owners, they are incentivised through long term investment to work within a target.

The engineering construction sector have long used target cost contracts for example the water sector and the standard contracts issued by the Institute of Chemical

\footnotetext{
${ }^{4}$ Royal Institution of Chartered Surveyors www.rics.org
} 
Engineers. There exist a number of variations of this type of contract in the UK. TCCs provide a mechanism to build to a budget. A widespread version is a "cost plus incentive fee" agreement that is believed to incorporate incentives for the contractor to reduce the capital construction cost. According to National Economic Development Office "target cost contracts specify a best estimate of the cost of the work to be carried out. During the course of the work, the initial target cost will be adjusted by agreement between the client or his nominated representative and the contractor to allow for any changes to the original specification. Difference between target cost and actual cost at completion are shared between the parties to the contract" (NEDO, 1982).

A pain/gain sharing mechanism is the distinguishing feature of these contracts. When cost overrun takes place it is assumed that it happened at least in part due to the contractor's inefficiency, thus there is no reason for the client to carry full responsibility for these extra expenses. When the situation is opposite and the contractor completes a job below target cost, he should be rewarded for his efficient management (Bagnall, 1990; Badenfelt, 2008; Chan et al., 2010). The sharing ratio is agreed in advance and varies from a simple 50:50 to complex mechanisms of benefits and risks sharing (Perry and Barnes, 2000; Broome and Perry, 2002; Badenfelt, 2008).

Target cost contracts often support partnering and/or alliance agreements with contractors (Bresnen and Marshall, 2000; Eriksson and Pesamaa, 2007; Lahdenperä, 2009; Bajari and Tadelis, 2001). In partnering arrangements a compensation based on financial incentives is believed to be important as it is supposed to allow all participating actors to gain the benefits of increased cooperation and integration between design and construction (Egan, 1998; Bayliss et al., 2004).

Despite the similarities the contract and cost management techniques and TCCs described above have with the manufacturing Target Costing concept illustrated in the 
previous chapter, they are essentially different in purposes, functions of targets, and implementation process.

One of the first examples of application of the original Target Costing concept in the project-based industry was BP's Project Andrew, reported by Knott (1996). Using the approach on the engineering and construction of a large-scale oil and gas platform resulted in vast improvement and around 30\% savings. Nicolini et al. (2000) analyses the application of Target Costing in the UK construction industry based on two case studies of the Ministry of Defence projects. Although the project's participants felt significant improvement of the project operation, they could not enjoy the full benefits due to several obstacles, the most important of which was the UK commercial and cost management practice. Several papers reporting successful application were published by the lean construction community, for example Pennanen et al. (2010) who provides evidence of positive adaptation of Target Costing in the Finnish market.

To the authors' knowledge the discussion of the original Target Costing in the construction research community is limited to the publications in the previous paragraph. It is neither mentioned in the popular construction cost management textbooks, e.g. Kirkham (2007), nor can it be found among the cost control methods widely used by practitioners (Olawale and Sun, 2010). Thus despite pressure to embrace learning from other sectors such as aerospace (Green et al., 2005) and automotive (Egan, 1998), Target Costing has not attracted much attention.

\section{Target Value Design}

Introduction of the Target Value Design technique is another attempt to bring and anchor the Target Costing practice in the construction industry. The main idea of TVD is to make a client's value (specific design criteria, cost, schedule, and constructability) a driver of design, thereby reducing waste and satisfying or even exceeding the client's expectations. A set of processes was developed that help to define client's value and 
make it drive the design. The processes and tools that TVD uses, e.g. cost estimating or financial incentives, are both new and traditional ones, although the function of the latter is altered. The operational excellence is achieved due to enhanced value and primary attention on the design stage as well as lean methods of work. Lean plays a role of the management philosophy. The lean principles, such as 'only do work on request', are in the service of generating value for customers and eliminating waste. Their applicability varies with the type and scope of work to which they are applied, and also with the receptivity of affected individuals and organisations.

The TVD processes were created, tested and improved through experimentations on projects first by Boldt Construction (St. Olaf's Tostrud Fieldhouse and Thedacare's Shawano Clinic projects), then by Sutter Health in the USA in association with their supply chain. As the experiments continue, both the take-up and processes employed in TVD keep evolving. Today it strongly relies at the systemic approach: joining TC principles with other factors, such as project organisation, commercial terms based on economic and non-economic motivation, lean system of operation, and striving for a change of culture.

\section{TVD Case Studies}

\section{Cathedral Hill Hospital Project}

Sutter Health is the largest healthcare company in Northern California. An initial attempt to design Sutter Health's Cathedral Hill Hospital Project, sited in downtown San Francisco, was terminated in 2005 at $\$ 400$ million over budget. Numerous changes in scope and big batch estimating together broke the link between scope and cost. The project team lost control of the project. In 2006, a new team was formed to make another attempt, this time using Target Value Design and lean project delivery. Sutter Health set a goal of providing $90 \%$ of the previous scope in $70 \%$ of the space. Converting that into a cost estimate resulted in an allowable cost for construction. 
Benchmarking against actual costs for similar projects revealed a 14\% gap between that allowable cost and the market cost. To validate the feasibility of closing that gap, the key members of the team that would deliver the project if funded, were engaged on professional services contracts. That team consisted of the architectural firm, the construction manager/general contractor, the electrical, structural and mechanical engineering firms, and the corresponding specialty contracting firms.

The team, working closely with Sutter Health, spent three months studying the problem and producing a report. In that time, the extent of design was a massing model with functions allocated to spaces. Narrative bases of design were developed for architecture and the major building systems represented on the team. Project team members understood that their cost of work would be reimbursed, and that fees, covering profit and overhead, would be fixed and that $25 \%$ of those fees would be at risk for failing to design and construct to budget.

\section{'Insert Figure 1 here'}

As shown in Figure 1, in September 2007 at the end of the business plan validation phase, a gap of $\$ 60$ million remained between what Sutter Health was willing (and able) to spend and the market cost benchmark. Despite that fact, the project team recommended funding at the allowable cost, confident that they could reduce the cost through innovations in design. That goal was accomplished in approximately 14 months, from 25th September 2007 to 9 th December 2008. Once the cost estimate was sufficiently below the budget to assure economic feasibility, a target cost was set $\$ 70$ million below the budget and Sutter Health and members of the project team developed a method for sharing cost savings.

At the end of October 2011, the cost estimate for the project was $\$ 25$ million below budget and the focus had shifted from seeking innovations in product design to seeking innovations in process design. 


\section{Fairfield Medical Office Building}

Sutter Health's Fairfield Medical Office Building is an example of a completed project employing the same form of contract and the same lean management methods as Cathedral Hill, including Target Value Design. As shown in Figure 2, the target cost and budget were set at $\$ 18.9$ million, $\$ 3.1$ million below the market cost benchmark, and the actual cost at completion was $\$ 17.9$ million, $\$ 4.1$ million (18.6\%) below the benchmark.

\section{'Insert Figure 2 here'}

Figure 3 shows the change in the project cost estimate over time, from the beginning of design to completion of construction. Black area represents the cost savings invested in value-adding features of the facility. Note that Target Value Design projects experience scope changes. Budgets, the boundary between painsharing and gainsharing, are adjusted accordingly.

\section{'Insert Figure 3 here'}

Table 1 shows cost performance or projects for 12 Target Value Design projects, which on average have underrun market costs by $15 \%$.

'Insert Table 1 here'

\section{Is Target Value Design something really different?}

In this section a comparison of Target Value Design and traditional contract and cost management is provided. The difficulty the authors faced when comparing the two alternatives is that they do not belong to the same category. TVD is a part of the strategic way of project delivery, from inception to completion, thus it includes a set of tools linked with each other in a continuous process and is based on lean management philosophy (Figure 4). What it is compared to - contract and cost management practice, 
DBOT procurement method, target cost contracts - are the discrete tasks or tools that influence only part of the project delivery system. And precisely for this reason the authors believe that the comparison is necessary as it aims to show that the success lies in the systemic approach. The decision of companies, e.g. Sutter Health, to adopt TVD means changes in the way the client works with the supply chain, how the project is procured and delivered. While by saying "target costing was applied on our project" a project manager on the not TVD project would probably mean that a target cost contract was in place.

\section{'Insert Figure 4 here'}

A summary comparing the two practices is provided in the Table 2 . The differences concern the process of setting the target cost and it management, role of the client and the supply chain in this process as well as the commercial structure of the deal and types of contracts.

'Insert Table 2 here'

\section{Project definition}

The process of setting a target is one of the key differences between TVD and cost planning. The early testing of the Target Costing approach on a St. Olaf's Tostrud Fieldhouse project (case 1, Table 1) started after schematic design. However the participants realised that a considerably greater results could be achieved if more attention be paid to the earlier stages of the project (Ballard and Reiser, 2004). It now seems optimal to dedicate a significantly greater time and effort to the predesign/project definition stage with the key downstream players involved in business planning, either directly, which has occurred occasionally, or through validation of the project business plan. The aim is to define value (desired features and functions) of the facility, and constraints, first of all financial - what the client is able and willing to pay 
to get this value. The latter is called an allowable cost. Both value and the allowable cost are derived from the operation model of the clients' business, not from the estimates.

How to understand if the defined allowable cost is an adequate sum for the construction of the desired value? Benchmarking against the market helps to answer this question. If the allowable cost is substantially below market, the client may choose to rethink what's wanted in order to reduce the gap. If the gap between the market price and the allowable cost is reasonable a feasibility study is launched and this is the next step in the processes. The feasibility study researches further into how to achieve stakeholders' values within financial constraints. Calculations of the expected cost provided by the project team are compared with the allowable cost. If the latter is smaller a conversation starts searching for a trade-off between what is wanted, how much it costs and what can be done to get it (Figure 5). Based on the results of the feasibility study, the client takes a final decision whether to proceed or not with funding the project.

\section{'Insert Figure 5 here'}

Target cost for the project is an outcome of the feasibility study and is the figure the design team is going to work to. The calculus includes all variables - allowable, expected, market cost, in their different possible quantitative relationships. Benchmarking to the market is used only to understand how realistic the target is and to assess the risk. The target cost may be set at the allowable cost if the latter is below market, though a more aggressive one may be accepted once the client and project team are confident the allowable cost can be achieved.

Cost planning also comes up with a target at the end of the seemingly similar process - business planning, feasibility study, setting a budget constraint for the design stage. However, there are significant differences in how the figure is derived. First of 
all, cost targets are estimate driven, not business case driven. Here it is necessary to distinguish among different types of clients. It is more typical for developers to derive the cost target from the business case due to their clear profit orientation, and in this sense the process they are going through is similar to the TVD one. For both public clients and clients building for their own use, the cost constraints are not that clear (Kirkham, 2007). In such situations TVD insists on developing the business case to understand clients' needs (in terms of end customer value, organisation's values and financial constraints), derives the allowable cost from the business case, carries out a feasibility study and sets a target cost as a result of it.

In the traditional cost planning the two mentioned types of clients would also develop a business case and set a target figure for budget based on cost estimates. Typically this is a product of an average market cost of the facility of that type and/or unit based calculations. After the business case is approved by the government (in case of public projects), by a relevant authority of a company, the sum corresponding to the cost estimate is committed. Thus the cost estimate figure becomes a guideline for the client's construction budget and a benchmark (target) for the cost control at the design stage (see, e.g. the case of the UK rail sector in Gannon and Smith, 2010).

Setting targets based on business case, not on cost estimates, not only helps to achieve better value, but also temper the impact of contingency. The degree of variation in construction projects generates a high level of uncertainty that each supply chain company protects themselves from with a risk contingency. It is either added into the unit rates by the contractor's estimator or included later during a commercial adjudication process before submitting the bid - or both. It is common practice for the Client's QS not only to use market prices that already include the contractor's risk contingency when estimating but to add a further percentage to cover price and design risk (Ferry et al., 1999). 
Second, traditional business planning stage is run by the client team almost in full isolation and the feasibility study is typically passed to the cost advisors with some client involvement. Although the cost advisors' function can be performed by a main contractor or a designer, in any case they are almost never the same people that carry out the downstream work. Thus the cost target is given to the design team, not set by it. In TVD as a result of joint work at the project definition all parties understand exactly what should be delivered and at what cost. This has consequences not only for quality of design, but also the team's motivation to reduce the cost.

Third, many questions concerning the definition of scope, its adjustment to the financial constraints, identification of cost saving opportunities are traditionally left to be dealt with at the design stage, while in TVD they are solved already during the feasibility study. This might mean greater expenditures at the early stages of the project, but the experiments with TVD show that this pays off in savings downstream. Early research is essential for informing the investment decision - to fund the project or not before design actually commences and eliminating the risk of abandoning the project late in the design after much more money are spent.

Finally, the cost target developed by the client (or other purchasing side in the supply chain) aims solely to guess a tender price or is used by the contracting side to look attractively cheap during the negotiation process. A better term for such practice might be "target pricing" as suggested by Nicolini et al. (2000). In contrast, target cost is the goal set for the final construction cost.

Engaging designers and builders in validating the business plan (where those designers and builders will actually deliver the project if funded) and anchoring targets in the allowable cost may be the fundamental differentiator of TVD from the target costing practices in construction. For an effective dialogue and a trusting relationship, the client has to be open and clear about the allowable cost and involvement of the 
team. The investment at the project definition stage naturally depends on the complexity of the project.

\section{Cost and target management in design}

More distinction comes if one looks at the way targets are actually managed at the design stage. In TVD target cost and value are extended from asset level to systems level and managed by cross functional teams organised correspondingly - e.g. envelope, structure, mechanical, electrical, plumbing, etc. Each of such clusters designs to its own cluster target cost. The value creation process is linked tightly with cost information estimates are provided continuously through close collaboration among the cluster members. Such 'over the shoulder estimating' is done frequently to prevent the risk of running above the target cost. Example from the Cathedral Hill hospital project: cluster cost estimates were updated and shared in weekly meetings of TVD team coordinators and discipline leads, open to all project team members. The project cost estimate is updated frequently to reflect TVD team updates.

TVD often starts with cost estimates considerably greater than the target and moves towards it or below through designing to cost. The latter implies a collaborative effort, timely information about buildability (design solutions that cannot be built or are too expensive to build are simply not developed further) and optimisation of each element early in the design. All drawing strongly rely on Value Management/Engineering principles and practices incorporated in the design process to capture the best ideas from everyone in the team at the earliest and most effective point. Builders have an important role to play in this process. They participate in generation, evaluation, and selection of design options; not limited to constructability. Target cost can never be surpassed as it would mean damage for the client's business. But conditions of satisfaction remain flexible to spur innovation and might be reviewed with agreement of the whole team as the design proceeds. 
Cost target in the cost planning process often changes as the certainty of the estimate grows. As design proceeds from an outline to a detailed costing of production drawings it might be that the building the client wants costs less or, which is more likely, more forcing the client to increase budget to conform to the current design development (Ferry et al., 1999).

The cost control function concentrates on costing the design drawings (Kirkham, 2007). Cost advisors work separated from designers and step in for scheduled cost reviews. Filling the design with specifications till it reaches the cost target is allowed indeed it is the nature of commercial practice to do as much work as possible spending the client's budget to create cash flow and turnover for the business. If the design goes beyond the cost target it is brought back to the original figure with cost cutting measures (or the target is changed). Cost cutting often commences prior to bidding through lowering specifications, reducing quality and trimming profit and focuses on cutting costs per se rather than on clients' value (Nicolini et al., 2000). Unplanned loopbacks and rework are common.

There is little variation to this process even when the design is more closely aligned to the supply side through early contractor involvement as project documentation is simply forwarded from one party to another, and the cost lags design rather than steers it. Many PFI/PPP projects have been heavily criticised for not delivering value or reducing cost due to absence of incentives to change the intention to maximise cost within the target. Demirag et al. (2004) provide a comprehensive review of the criticism demonstrating whether intentionally or not, the parties to the contracts are spending more money than they should. Although similar terms are in use designing to cost - the likeness between TVD and widespread practices of design cost management is superficial. The proactive approach - design to cost and value - helped 
by the alternative arrangement of the team is another major difference between these approaches.

\section{Systemic approach - project organisation}

TVD is a management practice rather than a type of contract or simply a cost control technique. That is why a discussion around wider managerial issues cannot be avoided if one wants to achieve a deeper understanding of the differences between TVD and traditional construction. Thomsen et al. (2009) demonstrate that project delivery can be treated as a system that consists of three elements: the project organisation, the project's “operating system," and the commercial terms that bind the project participants. The structure in each of these elements that must be aligned or in balance to achieve the targets, otherwise the outcomes are likely to be less than optimal (ibid). TVD alters the three elements and populates them with lean methods of work. These are the means to achieve the ends (targets).

Project organisation deals with procurement routes and management of the interorganisational relationships before and in course of the project. Most of the projects are organised as a sequential process, with the various specialists brought onto it only when their specific work is to be done. The result is emergence of multiple interfaces between firms, teams and departments that cause information loss and loss of the potential benefits that could be generated in synergy. An alternative, lean way of thinking that underpins TVD strives to have all relevant design criteria applied when evaluating and selecting from design alternatives, whether design of product or of process. Since these design criteria are resident in industry practitioners, the only way to assure that the right people are involved at the right time is to have them on the project team before their specific tasks are to be performed; e.g., to have the mechanical contractor engaged before they are to install ductwork and chillers. This idea is evident in the organisation created to validate business plans, consisting as it does of the key design and 
construction professionals who will deliver the project if funded. It is not simply a remote process, but real participation of the integrated team in the clients' business planning.

Selecting right people for the project is crucial for success as it sets a proper basis for cooperation (Brown et al., 2001; Erikson and Pesamaa, 2007). For success of the TVD processes procurement should be adapted to the needs of the project delivery system and value optimisation requirement. Competitive tenders are better avoided when possible (including tendering for the construction work) to preserve the accumulated knowledge. Ideally selection of the team should be based on interviews, consideration of companies' experience and their desire to follow lean principles in work.

This contrasts with traditional lowest bid procurement routes and those partnerships and PFI practices, where a "good will" agreement is signed between the client and the main contractor and the rest of the supply chain is hired using traditional tendering methods and contracts (Hughes et al., 2007). Having studied several partnering projects Dainty et al. (2001) concluded that for the majority of subcontractors their relationships with upper supply chain remained 'business as usual'.

Alternative project organisation establishes a different pattern of information flow and this is another major distinguishing feature of TVD. The goal is to achieve a shared understanding early in the design and sustain it over the whole project relying on the continuity of the teams' composition.

\section{Systemic approach - operating system}

Project organisation alone is not enough for collaboration. The process doesn't finish with signing an IPD or a partnering agreement between companies, the real challenge is to make these companies' staff work as one team on a daily basis. The lean operating system is absolutely necessary to make this happen. Technologies such as computer 
modelling are vital catalysts as well, as they enable transparency and promote shared understanding.

The optimal for the TVD operating system involves lean tools and methods of managing design and construction. There is a range of those borrowed directly from manufacturing or developed by the lean construction community: set-based and evidence-based design, A3 reports, Last Planner, Plan-Do-Check-Act cycle, etc. Parttime or even full-time co-residing and collocation with meetings held at least weekly is an essential feature.

In current construction there is still little understanding of what collaboration really means, what actions it implies and what responsibilities it puts on collaborating parties. Research on partnering projects carried out with 30 specialist contractors demonstrated that in a significant number of cases knowledge of partnering was limited only to senior management (Mason, 2007). Absence of a systemic approach to partnership affects strongly the ability to put the rhetoric of collaboration into practice (Bresnen and Marshall, 2000). It is not enough to 'play nice', collaboration only works when there is a change in the way work is done. For that, tools can be useful and sometimes even necessary, but are not sufficient to cause the needed change in attitude and behaviour. Creating a lean culture requires leadership.

\section{Systemic approach - commercial terms and risk management}

Commercial terms - contract, risk and remuneration - have a special role to play in establishing relationships between individuals and companies at the projects. Target cost contract, often referred to as a mechanism to achieve the cost targets set for the construction stage is the construction industry method. TVD uses relational contracts. Although both are structured around pain/gain share mechanism they differ very much in how this mechanism is actually used. 
Although there are cases when TVD worked on the basis of transactional multiparty contractual arrangement it was noticed that relational contracts provide better support for project of this kind. Relational contracts, such as the Integrated Form of Agreement ${ }^{5}$, are those in which a client engages a team of industry professionals to help them solve a problem, as opposed to buying a product. It aims at aligning the interest of all parties participating in the project and thus to create a proper collaborative base on which the relationships can be built. The agreement is signed early in the design process $^{6}$.

Commercial terms included in such contracts for TVD imply separation of profits from the costs and contingencies. Stakeholders' corporate profits are typically a pre-agreed lump sum calculated as a percentage of the project target cost, recalculated regularly according to the performance of the integrated team against project goals. All or part of the profit is at risk in case of cost overrun or reimbursed/shared if final cost equals or is less than the target cost (pain/gain share mechanism). The team receives incentives to reduce the direct costs for the project as the more it saves the higher profits each company gets. The sharing mechanism relies on the non-cost factors as well such as schedule and quality depending on what is important for the client (Mauck et al., 2009). Contingencies are transparent and managed by the IPD team separately from the project costs and profit fees. The contingency pot covers the problems that might occur both in design and construction.

Commercial terms for TVD do not intend to distribute risk but to understand and share it. This is a one-for-all, all-for-one type of agreement covering with equal terms all the participants. The mechanism to reduce risk lies in the organisation and operating

\footnotetext{
${ }^{5}$ Integrated Form of Agreement (IFoA) - a relational type of contract developed by Will Lichtig of McDonough Holland \& Allen. A generic form of the IFOA is provided free to the industry by the Lean Construction Institute. Other forms of relational contract include project alliancing, PPC2000, certain contract formats of the New Engineering and Construction Contracts, the American Institute of Architects' Integrated Project Delivery forms of contract, and certain contract forms offered by ConsensusDocs.

6 The project definition stage is typically covered by a separate agreement.
} 
system instead of being hidden in the commercial terms. The research on lean project delivery methods showed that risks associated with cost, quality, time and safety issues can be significantly reduced or even totally eliminated when lean thinking is implemented properly (Lichtig, 2006).

A target cost contract possesses none of these features. It belongs to the transactional type of agreements concluded after a tender between the client and the contractor. It is complemented with financial incentives that are believed to be enough to build trustworthy relationship. The agreement and the pain/gain share mechanism typically cover only the client and the contractor and do not include designers, subcontractors and suppliers. Thus neither client nor designers are involved in the cost reduction effort; it becomes solely the contractor's responsibility. There is no clear separation of profits and costs, contingencies are hidden in the price. The contract details tasks, reliabilities and penalties in case of non-performance and is then used as a tool to manage the contractors (Nicolini et al., 2000). Under Guaranteed Maximum Price (GMP) agreements, frequently used in TCC, risk pendulum swings to the contractor side even further. In its turn the contractor will not hesitate to shift the risks further down the supply chain. The problem is that risk shifting is only an illusion, as ultimately it is always the client to suffer the consequences. Should the problems occur, the project might be delivered late, with reduced specifications, not optimised life-cycle costs and poorer quality and might seriously harm the client's business.

TCC is a risk management tool that searches for the best distribution of risk among stakeholders. Clearly it is the opposite of the "three musketeers" attitude on the TVD projects. 


\section{Conclusions}

The adoption of Target Costing in the manufacturing industry demonstrated impressive results that naturally woke an interest in this approach. Through multiple self-reflective cycles of action research the concept of Target Costing was successfully adapted to the peculiarities of the construction industry under the name Target Value Design. TVD generates customer value within the customer's conditions of satisfaction; i.e., conditions such as time and cost that must be met in order for that value to be fully realised. Essential to TVD is the practice of designing to targets rather than designing, then checking whether budgets, schedules, etc. have been exceeded. Used consistently over time, this practice results in reduced costs for similar facilities, year on year.

The features of the TVD practice were demonstrated in this paper contrasting it with the traditional cost and contract management practice. The major distinguishing features of TVD were identified in 1) the project definition process - TVD roots target cost into the allowable cost and client's business goals as well as engages designers and builders in validating the business plan; 2) cost and target management - design to cost and value, decentralised management; 3) systemic approach to project management that aligns project organisation, operation system based on lean principles and commercial terms

The aim of the action research was to create a practical contribution to knowledge transferable to construction projects generally. One way to achieve it is through creation of process protocols and revealing those criteria that consistently affect implementation of the new routine. These were partly reported in the paper, e.g. Figures 4 and 5, and the comparison chapter.

The TVD process has been used in projects on which the client and key members of the project team all sign one contract, but can be equally applied on projects where the client is able to adequately specify what's wanted prior to design, so need not 
be a continuously active member of the project team. Design-Build and various forms of Private-Public Partnerships are among the viable alternatives.

TVD research and practice have been carried out within the lean philosophy framework and rely on lean processes and tools. Although in reality total transformation to lean is not always possible, it stays there as an ideal to be pursued. The possibility of TVD working under different management strategies has not been investigated. It was noticed however that the positive effects of lean principles and methods on project management become more obvious as project complexity and corresponding level of risk rises. The same dependency exists between level of risks and the need for TVD. Consequently, TVD is appropriate for all projects except:

- those that have been pre-designed, whether completely or requiring only minor adaptation to local conditions, and the design is sufficiently optimised that further investment is not likely to pay off;

- those for which the customer cannot find service providers that are capable and trusted to execute the TVD technique;

- those that are prohibited by statute from integrating organisationally, whether from prohibition of value based selection or from prohibiting design and construction roles for builders.

Two principles fundamental for TVD are: 1) enable money to flow across organisational and contractual boundaries in search of the best project-level investment, and 2) apply simultaneously all relevant design criteria to the generation, evaluation and selection from product and process design alternatives. The former is facilitated by the “Three Musketeer" commercial terms and the latter by involving downstream players in upstream processes, and vice-versa.

The current practice of TVD is also limited by a number of factors, including: 
- the lack of a rigorous basis for clients' determination of asset worth and allowable cost; e.g., an operations cost model;

- a need for an accurate method of benchmarking project costs from programmatic data;

- when cost savings are not assured until late in the design phase, limiting client investments in value-adding enhancements;

- a failure to adjust allowable costs, and hence project budgets, to changes in whole life costs and benefits from design innovations;

- an inflexibility of financing changes in the project budgets, even when the return on investment is otherwise compelling.

\section{REFERENCES}

Anderson, S.W. (2006) Managing costs and cost structure throughout the value chain: research on strategic cost management. Handbooks of Management Accounting Research, 2, 481-506.

Ansari, S. and Bell, J. and Okano, H. (2006) Target Costing: uncharted research territory. Handbooks of Management Accounting Research, 2, 507-530.

Badenfelt, U. (2008) The selection of sharing ratios in target cost contracts. Engineering Construction and Architectural Management, 15 (1), 54-65. Bagnall, B. (1990) Tenders and Contracts for Building, 2nd Edn. BSP Professional Books, pp. 83-89.

Bajari, P. and Tadelis, S. (2001) Incentives versus transaction costs: a theory of procurement contracts. Rand Journal of Economics, 32 (3), 387-407.

Ballard, G. (2000) Lean Project Delivery System, Lean Construction Institute White Paper N8, revision 1 [available at www.leanconstruction.org]. 
Ballard, G. and Reiser, P. (2004) The St. Olaf College Fieldhouse Project: A Case Study in Designing to Target Cost. Proceedings of the 12th Annual Conference of the International Group for Lean Construction, Elsinore, Denmark.

Bayliss, R. and Cheung, S.O. and Suen, H.C.H. and Wong, S.P. (2004) Effective partnering tools in construction: a case study on MTRC TKE contract 604 in Hong Kong. International Journal of Project Management, 22 (3), 253-263.

Reason, P. and Bradbury, H. (2007) The SAGE Handbook of Action Research: Participative Inquiry and Practice, 1st Edn. Sage, London.

Bresnen, M. and Marshall, N. (2000) Building partnerships: case studies of client contractor collaboration in the UK construction industry. Construction Management and Economics, 18 (7), 819-832.

Broome, J. and Perry, J. (2002) How practitioners set share fractions in target cost contracts. International Journal of Project Management, 20 (1), 59-66.

Brown, D.C. and Ashleigh, M.J. and Riley, M.J. and Shaw, R.D. (2001) New project procurement process. Journal of Management in Engineering, 17 (4), 192-201. Carr, C. and Ng, J. (1995) Total Cost control: Nissan and its UK supplier partnerships. Management Accounting Research, 6 (4), 347-365.

Chan, D.W.M. and Chan, A.P.C. and Lam, P.T.I. and Wong, J.M.W. (2010) An empirical survey of the motives and benefits of adopting guaranteed maximum price and target cost contracts in construction. International Journal of Project Management, $29(5), 577-590$.

Cooper, R. and Slagmulder, R. (2004) Interorganizational cost management and relational context. Accounting, Organizations and Society, 29 (1), 1-26.

Cooper, R. and Slagmulder, R. (1997) Target Costing and Value Engineering, Productivity Press, Portland, US. 
Cooper, R. and Kaplan, R. (1999) The Design of Cost Management Systems, Upper Saddle River: Prentice Hall, Inc.

Dainty, A. and Briscoe, G.H. and Millett, S.J. (2001) Subcontractor perspectives on supply chain alliances. Construction Management and Economics, 19 (8), 841-848 Demirag, I. and Dubnick, M. and Khadaroo, I. (2004) A Framework for examining accountability and value for money in the UK's private finance initiative. Journal of Corporate Citizenship, 15.

Egan, J. (1998) Rethinking Construction, Report of the Construction Task Force on the Scope for Improving the Quality and Efficiency of UK Construction, Department of the Environment, Transport and the Regions, London, UK.

Eriksson, P.E. and Pesamaa, O.P. (2007) Modelling procurement effects on cooperation. Construction Management and Economics, 25 (8), 893-901.

Feil, P. and Yook, K.H. and Kim, I.W. (2004) Japanese target costing: a historical perspective. International Journal of Strategic Cost Management, 10.

Ferry, D.J. and Brandon, P.S. and Ferry, J.D. (1999) Cost Planning of Buildings, 7th Edn. Blackwell Science, Oxford.

French, W.L. and Bell, C. (1973) Organization development: behavioral science interventions for organization improvement. Prentice-Hall, Englewood Cliffs, New Jersey

Gannon, M.J. and Smith, N.J. (2011) An effective outline business case to facilitate successful decision-making. Construction Management and Economics, 29 (2), 185 197.

Green, S.D. and Fernie, S. and Weller, S. (2005) Making sense of supply chain management: a comparative study of aerospace and construction. Construction Management and Economics, 23 (6), 579 - 593. 
Håkansson, H. and Lind, J. (2006) Accounting in an interorganizational setting. Handbooks of Management Accounting Research, 2, 885-902.

Hughes, W. and Yohannes, I. and Hillig, J.B. (2007) Incentives in construction contracts: should we pay for performance? CIB World Building Congress Proceedings, $2272-2283$.

Jacomit, A.M. and Granja, A.D. and Picchi, F.A. (2008) Target costing research analysis: reflections for construction industry implementation. Proceedings of the 16th Annual Conference of the International Group for Lean Construction, Manchester, UK. Kato, Y. (1993) Target costing support systems: lessons from leading Japanese companies. Management Accounting Research, 4 (1), 33-47.

Kato, Y. and Yoshida, E. (1998) Target cost management and organizational theories. Management Accounting Workshop, Kobe University Citeseer.

Khemlani, L. (2009) Sutter Medical Center Castro Valley: case study of an IPD project. AECbytes "Building the Future" [available at http://www.aecbytes.com/buildingthefuture/2009/Sutter_IPDCaseStudy.html] Kirkham, R.J. (2007) Ferry and Brandon's Cost Planning of Building, 8th Edn. Blackwell Publishing.

Knott, T. (1996) No Business as Usual, London, B.P. Education. Lahdenperä, P. (2009) Project alliance. The competitive Single Target-Cost Approach, Espoo 2009. VTT Tiedotteita, Research Notes 2472, 74.

Lewin, K. (1946) Action Research and Minority Problems. Journal of Social Issues, 2 (4), 34-46

Lichtig, W. (2006) The Integrated Agreement for Lean Project Delivery. Construction Lawyer, 26 (3), 1-8.

Lockamy, A. and Smith, W.I. (2000) Target costing for supply chain management: criteria and selection. Industrial Management and Data Systems, 100 (5), 210-218. 
Mason, J.R. (2007) The views and experiences of specialist contractors on partnering in the UK. Construction Management and Economics, 25 (5), 519-527

Mauck, R. and Lichtig, W. and Christian, D. and Darrington, J. (2009) Integrated project delivery: different outcomes, different rules. Proceedings from the 48th Annual Meeting of Invited Attorneys.

Monden, Y. and Hamada, K. (2000) Target Costing and Kaizen Costing in Japanese Automobile Companies, Ed. Y. Monden, World Scientific, 99.

(NAO, 2005).

National Economic Development Office (1982) Target Cost Contracts - A Worthwhile Alternative, Civil Engineering Economic Development Committee, National Economic Development Office, London.

Nicolini, D. and Tomkins, C. and Holti, R. and Oldman, A. and Smalley, M. (2000) Can target costing and whole life costing be applied in the construction industry?: evidence from two case studies. British Journal of Management, 11 (4), 303-324.

Olawale, Y.A. and Sun, M. (2010) Cost and time control of construction projects: inhibiting factors and mitigating measures in practice. Construction Management and Economics, 28 (5), 509-526.

Pennanen, A. and Ballard, G. and Haahtela, Y. (2010) Designing to targets in a target costing process. Proceedings of the 18th Annual Conference of the International Group for Lean Construction, Haifa, Israel.

Perry, J.G. and Barnes, M. (2000) Target cost contracts: an analysis of the interplay between fee, target, share and price. Engineering Construction and Architectural Management, 7 (2), 202-208.

Pratt, D.J. (2003) Fundamentals of construction estimating, 2nd Edn, Delmar Pub. Rains, J. (2010) Target Cost Management: The Ladder to Global Survival and Success, CRC Press. 
Shewhart, W.A. (1931) Economic Control of Quality of Manufactured Product, Van Nostrand, New York, NY.

Tani, T. (1995) Interactive control in target cost management. Management Accounting Research, 6(4), 399-414.

Thomsen, C. and Darrington, J. and Lichtig, W. (2009) Managing Integrated Project Delivery, CMAA College of Fellows, available at [http://cmaanet.org/fellows]

Tommelein, I.T. and Ballard, G. and Lee, H. W. (2011) Task 4 Progress Report:

Develop Target Value Design and Delivery Process to Incorporate Energy Efficiency Metrics, for the United States Department of Energy.

Yoshikawa, T. and Innes, J. and Mitchell, F. (1995) A Japanese Case Study of Functional Cost Analysis. Management Accounting Research, 6 (4), 415-432.

Table 1: Cost performance and projections for 12 TVD projects (from Tommelein, et al., 2011)

\begin{tabular}{ccccccc}
\hline \# & $\begin{array}{c}\text { Project } \\
\text { Size, } \\
000 \mathrm{SF}\end{array}$ & Stage & $\begin{array}{c}\text { Market Unit } \\
\text { Cost } \\
\text { (Benchmarked } \\
\text { or Expected), } \\
\text { doll. per SF }\end{array}$ & $\begin{array}{c}\text { Target Unit } \\
\text { Cost Set for } \\
\text { Designing, } \\
\text { doll. per SF }\end{array}$ & $\begin{array}{c}\text { Final Unit } \\
\text { Cost (Current } \\
\text { Estimate if } \\
\text { below Target), } \\
\text { doll. per SF }\end{array}$ & $\begin{array}{c}\text { Improvement } \\
\text { in \% } \\
\text { (Realised or } \\
\text { Targeted) }\end{array}$ \\
\hline 1 & 114,0 & Completed & 119,0 & n/a & 103,0 & $13 \%$ \\
2 & 230,0 & Completed & 96,0 & n/a & 78,0 & $19 \%$ \\
3 & 75,4 & Completed & 180,0 & n/a & 149,0 & $18 \%$ \\
4 & 477,0 & $\begin{array}{c}\text { Construction } \\
\text { documents }\end{array}$ & 440,0 & n/a & 393,0 & $11 \%$ \\
5 & 368,9 & Completed & 266,0 & n/a & 242,0 & $9 \%$ \\
6 & 30,0 & Completed & 483,0 & n/a & 457,0 & $6 \%$ \\
7 & 231,9 & Construction & 1332,0 & 989,0 & n/a & $26 \%$ \\
8 & 925,0 & $\begin{array}{c}\text { Construction } \\
\text { documents }\end{array}$ & 1200,0 & 1039,0 & n/a & $13 \%$ \\
\hline 9 & 869,0 & $\begin{array}{c}\text { Construction } \\
\text { documents }\end{array}$ & 2085,0 & 1825,0 & n/a & $12 \%$ \\
\hline
\end{tabular}




\begin{tabular}{ccccccc}
\hline 10 & 233,1 & $\begin{array}{c}\text { Design } \\
\text { development }\end{array}$ & 1342,0 & 1268,0 & $\mathrm{n} / \mathrm{a}$ & $6 \%$ \\
11 & 107,0 & $\begin{array}{c}\text { Design } \\
\text { development }\end{array}$ & 2626,0 & 2336,0 & $\mathrm{n} / \mathrm{a}$ & $11 \%$ \\
12 & 101,9 & Construction & 1601,0 & 1062,0 & $\mathrm{n} / \mathrm{a}$ & $34 \%$ \\
\hline
\end{tabular}

Table 2: Comparison of TVD and historic project delivery approaches - features

\section{Contract and cost management practices in construction}

Target Value Design
Strives to procure a constructed asset for the least price and keep the project cost under control with cost cutting measures.

Target is for guessing the tender price

Set by client with or without cost advisor, based on cost estimates (historical data and benchmarking).

Division of labour - designers do the design and cost advisors perform scheduled estimates of the work done.

Builders' role, if any, is limited to cost estimating and after-the-fact constructability reviews.

Costing the design. Value engineering as a firefighting measure. Cost targets change.

Occasional involvement in case problems occur.

Cost based selection.

Projects are organised as a sequential process. Poor information flow between the parties working at the project, no involvement of the
Objective of cost management

Function of cost targets

Target is for final construction cost

Setting a Set after a feasibility study rooted in target the client's business case.

Cross functional clusters manage cost and design to cluster targets. 'Over the shoulder estimating'.

Cost and target management in design

Role of client

Project organisation

Strives to procure a constructed asset for no more than its allowable cost while reducing the price paid through gainsharing.

Design solutions are developed with cost, schedule, and constructability as design criteria; built-in value engineering.

Target Cost cannot be exceeded, value targets are stretch goals to spur innovation.

A active and permanent member of the project delivery team throughout the project duration.

Value based selection.

IPD team is formed at the business planning stage). Full engagement of all the key players in the design 
downstream players.

No staff continuity.

Project management tools.

A set of transaction contracts.

Contracts as a control tool. Incentives are better fitted for local optimisation.

Monetary motivation.

Pain/gain share does not distinguish among cost, profits and contingencies.

Risk shifting down the supply chain.

Contract as risk management tools, risk is hidden in the commercial terms. process.

Continuity of staff to retain the knowledge.

Operating

system

Co-location, at least weekly team meetings. Lean set of tools to eliminate process waste.

Relational contract covers the key players.

Commercial The incentives of all team members terms and are aligned with pursuit of project role of objectives.

contract

Monetary and non-monetary motivation. Separation of cost from profits and contingencies.

All for one, one for all thinking.

Risk Collaborative decision-making.

management Risk reduction thanks to the lean organisation and operating system. 